\section{A fine neuroscience vintage}

\author{
Matthew C Kiernan
}

I recently bumped into a cardiologist mate who had just won a silver medal for his first wild barrel ferment Chardonnay from the vineyard he started with a haematologist, their wine label aptly named Blood Brothers. He told me his approach to cultivating a fine harvest. While many factors play a role he said, the raw product and how it is nurtured, remains the key. The grape variety and how it responds to the prevailing climate at the time of harvest are the critical factors in producing a fine wine vintage. After our conversation, I was impelled to draw a parallel between his wine making and the process of extracting practical and elegant medical research from a sea of data. For although there has been a significant increase in the number of new journals covering the clinical neurosciences, the raw product-that is, the original research question and how it is nurtured by the scientific authorsremains the critical ingredient.

From the Journal perspective, the boom in neuroscience research has led to a substantial increase in the number of submissions for all journals. As a result, the success of all research endeavours relies more than ever on it being unique, with innovative translation and impact to the care of patients, highly readable and eminently quotable, no mean feat! Although even the most successful submissions may require fine tuning and editing, the best of clinical neuroscience will always rise to the top.

Neuroscience, just as with any medical field, is predicated on an urgency in the development of novel therapeutic approaches and indeed targets. However, the field of neuroscience is one that is expanding exponentially as the world population ages. According to the WHO's large-scale studies, about a third of the adult worldwide population suffer from neurological disorders such as dementia and stroke; and disorders of mental health such as depression and anxiety. Taken together, these 'disorders of the brain' account for $13 \%$ of the global disease burden. This surpasses cardiovascular diseases (5\%) and cancer (10\%)-alarming statistics. No country is spared.

Correspondence to Professor Matthew C Kiernan, Bushell Chair of Neurology, Brain and Mind Research Institute, University of Sydney, Sydney, NSW 2040, Australia; matthew.kiernan@sydney.edu.au
Consequently, various new government Brain initiatives such as that recently announced by President Obama (BRAIN: Brain Research through Advancing Innovative Neurotechnologies), in which he agreed to invest an initial $\$ 100$ million for the fiscal year 2014, are particularly timely. A Whitehouse spokesperson couched the Brain initiative as one that had the potential to do for neuroscience what the human genome project had done for genomics. Put simply, its aim is the development of innovative technologies that will provide dynamic 'real life' understanding of the brain and its mechanisms.

Such an initiative will necessarily rely on partnership with business, but perhaps more importantly, philanthropy. And what better way to encourage and drive such partnership than by showcasing the best that clinical neuroscience has to offer. In line with such a goal, the JNNP Editorial team meets via teleconference from all corners of the globe on a weekly basis to form The Hanging Committee. Rather than gallows humour, The Hanging
Committee has the privilege of considering the finest manuscripts submitted to the journal over the past 7 days, discussing the critical messages from each, to determine which will be published in the Journal and be representative of our ambition-to publish ground-breaking and cutting-edge research from around the world. Encompassing the entire genre of neurological sciences, our focus is on the common disorders (stroke, multiple sclerosis, Parkinson's disease, epilepsy, peripheral neuropathy, subarachnoid haemorrhage and neuropsychiatry), but with a keen interest in the Gordian knots that present themselves in the field, such as amyotrophic lateral sclerosis or Huntington's disease. ${ }^{1-11}$ With early online publication, regular podcasts and an immense archive collection, with the longest half-life of any journal in clinical neuroscience, JNNP is a trailblazer and not a follower.

Potential citation classics arise each day and it is our job to identify them and bring them to the attention of the field as possible. With the diverse team of practising clinicians on the JNNP Editorial Committee, it is always our goal to identify the manuscripts that start with a bang and continue to age better with time, akin to the fine wine vintages of tomorrow. 


\section{Competing interests None.}

Provenance and peer review Not commissioned; internally peer reviewed.

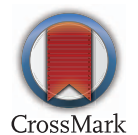

To cite Kiernan MC. J Neurol Neurosurg Psychiatry 2015;86:1-2.

Received 10 November 2014 Accepted 10 November 2014

J Neurol Neurosurg Psychiatry 2015;86:1-2. doi:10.1136/jnnp-2014-309899

\section{REFERENCES}

1 Richardson MP. Large scale brain models of epilepsy: dynamics meets connectomics. J Neurol Neurosurg Psychiatry 2012;83:1238-48.
2 Inui K, Kakigi R. Pain perception in humans: use of intraepidermal electrical stimulation. J Neurol Neurosurg Psychiatry 2012;83:551-6.

3 Phukan J, Elamin M, Bede P, et al. The syndrome of cognitive impairment in amyotrophic lateral sclerosis: a population-based study. J Neurol Neurosurg Psychiatry 2012;83:102-8.

4 Zuliani L, Graus F, Giometto B, et al. Central nervous system neuronal surface antibody associated syndromes: review and guidelines for recognition. I Neurol Neurosurg Psychiatry 2012;83:638-45.

5 Charidimou A, Gang Q, Werring DJ. Sporadic cerebral amyloid angiopathy revisited: recent insights into pathophysiology and clinical spectrum. I Neurol Neurosurg Psychiatry 2012;83:124-37.

6 Krishnadas R, Cavanagh J. Depression: an inflammatory illness? J Neurol Neurosurg Psychiatry 2012;83:495-502.

7 Soilu-Hanninen M, Aivo J, Lindstrom BM, et al. A randomised, double blind, placebo controlled trial with vitamin D-3 as an add on treatment to interferon beta- $1 \mathrm{~b}$ in patients with multiple sclerosis. J Neurol Neurosurg Psychiatry 2012;83:566-72.

8 Murphy SM, Laura M, Fawcett $\mathrm{K}$, et al. Charcot-Marie-Tooth disease: frequency of genetic subtypes and guidelines for genetic testing. I Neurol Neurosurg Psychiatry 2012;83:706-10.

9 Khan BK, Yokoyama JS, Takada LT, et al. Atypical, slowly progressive behavioural variant frontotemporal dementia associated with C90RF72 hexanucleotide expansion . J Neurol Neurosurg Psychiatry 2012;83:358-64.

10 Hou R, Moss-Morris R, Peveler R, et al. When a minor head injury results in enduring symptoms: a prospective investigation of risk factors for postconcussional syndrome after mild traumatic brain injury. I Neurol Neurosurg Psychiatry 2012;83:217-23.

11 Melzer TR, Watts R, MacAskill MR, et al. Grey matter atrophy in cognitively impaired Parkinson's disease. J Neurol Neurosurg Psychiatry 2012;83:188-94. 